\title{
Kısmi Gölgelenme Durumundaki Seri Bağlı Fotovoltaik (FV) Panellerde Bypass Diyotunun Kullanılmasının Sistem Gücü Üzerine Etkisi
}

\section{The Effect of Using Bypass Diode in Series Connected Photovoltaic (PV) Panels on System Power in Partial Shading Condition}

\author{
Akif Karafil 1* \\ ${ }^{1}$ Yalova Üniversitesi Mühendislik Fakültesi Elektrik-Elektronik Mühendisliği Bölümü, Yalova, TÜRKIYE \\ Sorumlu Yazar / Corresponding Author*: akif.karafil@yalova.edu.tr \\ Geliş Tarihi / Received: 04.09.2020 Araştırma Makalesi/Research Article \\ Kabul Tarihi / Accepted: 26.11.2020 DOI:10.21205/deufmd.2021236823 \\ Atıf sekli/How to cite: KARAFiL A.(2021). Kısmi Gölgelenme Durumundaki Seri Bağll Fotovoltaik (FV) Panellerde Bypass Diyotunun \\ Kullanılmasının Sistem Gücü Üzerine Etkisi. DEÜFMD 23(68), 621-630.
}

\section{Öz}

Gerilimin yüksek değerde olması istenilen fotovoltaik (FV) sistemlerde paneller seri olarak bağlanır. Seri bağlanan FV sistemlerde en önemli sorunlardan biri bina, ağaç, direk vb. nedenlerden dolayı panel üzerinde kısmi gölgenin oluşmasıdır. Kısmi gölgeleme, panel üzerinde sıcak noktaların oluşmasını neden olarak hem panele zarar verir hem de sistemin verimini düşürür. Bu olumsuz durumların engellenebilmesi için panellere paralel olarak bypass diyotları bağlanır. Bu çalışmada, kısmi gölgelenme durumundaki seri bağlı FV panel sayısının sırasıyla 2, 4 ve 6 olacak șekilde arttırılarak sistemde bypass diyotunun kullanılıp kullanılmamasına göre meydana gelen kayıp oranı incelenmiştir. Panel sayısı arttırılırken sistemin toplam gölgelenme oranı da azaltılmıştır. Çalışma, PSIM benzetim programı kullanılarak gerçekleştirilmiștir. Yapılan inceleme sonucunda kısmi gölgelenmeye maruz kalmış seri bağlı FV panellerde panel sayısı arttırılıp toplam gölgelenme oranı düștükçe bypass diyotunun kullanıldığı sistemlerde kayıp oranı azalmaktadır. Bypass diyotunun kullanılmadığı sistemlerde ise panel sayısı arttırılıp toplam gölgelenme oranının düşürülmesi kayıp oranını azaltmamakta aksine arttırmaktadır. Yani; bypass diyotsuz sistemlerde seri bağlı FV panel sayısı arttırıldığında düşük gölgelenme oranlarının bile verimliliği önemli ölçüde düşürdüğü görülmüştür.

Anahtar Kelimeler: Kısmi Gölgelenme, Bypass Diyot, Fotovoltaik Panel

\begin{abstract}
Panels are connected in series in photovoltaic (PV) systems where high voltage is desired. One of the most important problems in PV systems connected in series is the formation of partial shading due to the factors as building, tree, pole etc. Partial shading causes the formation of hot spots on the panel, damaging the panel and reducing the efficiency of the system. In order to prevent these negative situations, bypass diodes are connected parallel to the panels. In this study, the number of PV panels connected in series in partial shading is increased in a way to be 2,4 and 6 , respectively, and therefore the rate of losses when the bypass diode is used and is not used not in the system are
\end{abstract}


investigated. While the number of panels was increased, the total shading rate of the system was also reduced. The study was carried out using the PSIM simulation program. As a result of the examination, as the number of panels in series connected PV panels and exposed to partial shading is increased and the total shading rate decreases, the loss rate in systems using bypass diodes decreases. On the contrary,in systems where bypass diode is not used, increasing the number of panels and decreasing the total shading rate does not reduce the loss rate. Therefore, it was seen that when the number of PV panels connected in series was increased in systems where bypass diode was not used, even low shading rates significantly reduced the efficiency.

Keywords: Partial Shading, Bypass Diode, Photovoltaic Panel

\section{Giriş}

Makineleşmiş olan endüstride gerekli olan elektrik enerjisinin elde edilmesi çoğunlukla kömür, petrol gibi fosil esash kaynaklar ile sağlanmaktadır. Her ne kadar günümüzde çoğunlukla petrol türevi kaynaklar kullanılsa da, bu kaynaklara alternatif olabilecek enerji kaynağı arayışları hızla devam etmektedir. Bu arayışların nedeni, fosil esaslı kaynakların yanması sonucu ortaya çıkan gazların çevreyi kirletmesi ve bu kaynakların yakın gelecekte tükenecek olmasıdır. Bunun sonucunda rüzgar, güneș, jeotermal, biokütle gibi yenilenebilir enerji kaynakları kullanılmaya başlanmıştır [13]. Elektrik enerjisinin üretiminde özellikle rüzgar ve güneş enerjisinin kullanımı, diğer yenilenebilir enerji kaynaklarına göre daha önde gelmektedir. Bu alanda yapılan teşvik ve yatırımlarla bu enerji kaynakları, fosil esaslı kaynaklar ile rekabet edebilir hale gelmiștir [4].

Mevcut alternatif enerji kaynakları içerisinde fotovoltaik (FV) enerji en önemli yenilenebilir enerji kaynaklarından biridir. FV enerjinin temiz ve kurulumlarının basit olması, çok fazla bakıma ihtiyaç duymamaları ve megavatlara kadar güç sağlayabilmeleri bu enerji kaynaklarının en önemli avantajlarıdır. Aynı zamanda su pompaları, güneş ev sistemleri, şebekeden uzak binalar gibi birçok alanlarda yaygın olarak kullanılmaya başlanması FV enerjiye olan talebi her geçen gün arttırmaktadır. Fakat, FV panel veriminin düşük olması, atmosferik şartların gün içerisinde değișiklik göstermesi ve buna bağlı olarak FV panellerinden elde edilen güç değerlerinin de sürekli olarak değișmesi FV enerji sistemlerinin en önemli dezavantajlarını oluşturmaktadır [56].

FV hücreler seri bağlanarak FV paneli olușturur. FV panel, seri bağlanan hücre sayısı kadar çıkış gerilimi üretir. Akımın yeterli olduğu, fakat daha yüksek gerilim seviyesinin istendiği durumlarda
FV paneller seri bağlanarak çıkış gerilimi arttırılır. Seri bağlanan FV paneller her zaman eșit miktarda güneș ışınımına maruz kalamayabilir. Bulut, bina, direk, baca, ağaç vb. nedenlerden dolayı FV panelin/hücrelerin belirli bir kısmı gölgelenmeye maruz kalabilir. $\mathrm{Bu}$ duruma kısmi gölgelenme denir. Özellikle seri bağlı FV panellerde kısmi gölgelenme önemli bir sorun oluşturur. Seri bağll FV panellerden herhangi biri gölgelendiğinde gölgeli olan hücrelerde akım sıfır olur ve sistemin toplam akımı azalır. Bu durum gölgeli olan hücrelerin bir tüketici yük gibi davranmasına neden olarak güç kaybı olușturur. Aynı zamanda sistemin verimi de azalır. Güç kaybı, gölgeli hücrelerde ısı kaybı olarak ortaya çıkar ve panelin gölgelenmiş kısımlarında sıcak bölgeler oluşturur. Sıcak bölgeler verimi düşürmekle birlikte lehim yapılmış olan bağlantı yerlerine zarar vererek panelin hasar görmesine neden olur. $\mathrm{Bu}$ olumsuz durumların giderilebilmesi için bir bypass diyotu FV panele ters paralel olarak bağlanır [7-9]. Her bir hücreye bypass diyotunun bağlanması hem maliyetli hem de pratik değildir. Ayrıca bypass diyotunun aktif durumda belirli bir güç kaybına neden olacağı unutulmamalıdır. Bu yüzden hücre sayısı düşük olan FV panellerde, panel üreticileri bir veya iki bypass diyotu kullanırken, hücre sayısı fazla olan FV panellerde daha fazla bypass diyotu yer almaktadır. Bazı FV panellerde ise bypass diyotu bulunmayabilir. Özellikle sebekeden bağımsız sistemlerde paralel bağlanacak FV paneller için bypass diyotuna gerek yoktur [10].

Herhangi bir gölgelenme meydana gelmediğinde bypass diyotu pasif durumdadır. Gölgelenme gerçekleştiğinde ise FV akım, bypass diyotundan geçer ve bu sayede gölgelenmiş olan panel üzerinde sıcak noktaların oluşması engellenir. Fakat bypass diyotunun kullanılmasıyla birlikte sistemde bir genel güç noktası, bir veya birden fazla da yerel 
DEÜ FMD 23(68), 621-630, 2021

güç noktaları olușur. Eğer sistemde maksimum güç noktası takibi (MGNT) kullanılacaksa MGNT algoritmasında genel güç noktasının bulunması sağlanarak sistemin toplam gücünün düșmesi engellenir. $\mathrm{Bu}$ sayede sistem verimliliği de arttırılır [11-13].

$\mathrm{Bu}$ çalışmada, kısmi gölgenme durumundaki seri bağlı FV panellerde bypass diyotunun kullanılıp kullanılmamasının sistem gücü üzerine etkisi incelenmiştir. Çalışmada PSIM benzetim programı kullanılarak 2, 4 ve 6 adet seri bağlı FV panellerde toplam gölgelenme miktarı değiștirilerek bypass diyotlu ve diyotsuz sistemlerde meydana gelen kayıp güç miktarı analiz edilmiștir.

\section{Matematiksel Analiz}

\subsection{FV hücrenin matematiksel analizi}

FV panellerinden elde edilen akım, gerilim ve güç gibi değerlerin belirlenebilmesi için FV hücrenin eşdeğer devre modelinin çıkartılması gerekmektedir. FV hücre, p-n yarı iletken malzemelerden yapılmıștır. $\mathrm{Bu}$ yüzden $\mathrm{FV}$ hücre, elektroniğin en temel elemanlarından olan bir diyot ve ona paralel bağlı akım kaynağ ile sembolize edilmektedir. FV hücredeki kayıplar ise paralel-seri direnç ile temsil edilmektedir. FV hücrenin tek diyotlu eşdeğer devre modeli Şekil 1'de gösterilmiștir.

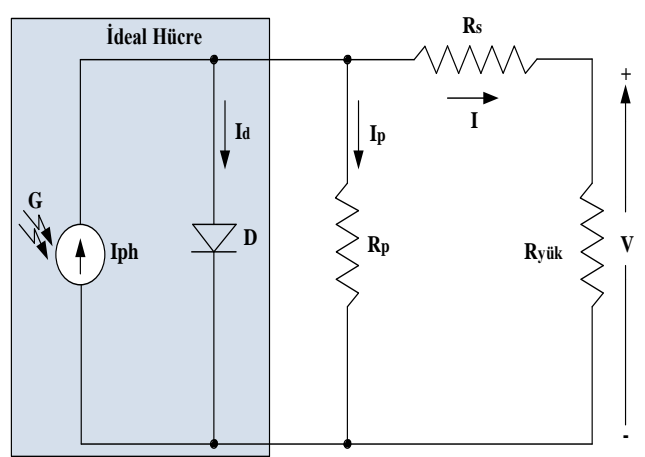

Şekil 1. FV hücrenin tek diyotlu eșdeğer devresi Şekil 1'deki devre modeline göre eșitlik (1) elde edilir.

$$
I=I_{p h}-I_{o}\left[e^{\left(\frac{q *\left(V+I * R_{S}\right)}{A * k * T}\right)}-1\right]-\frac{V+I * R_{S}}{R_{p}}
$$

Burada;

$I_{p h:}$ FV hücrede oluşan akım

$I_{o}$ : Ters sızıntı akımı $q$ : Elektrik yükü $\left(1,602^{*} 10^{-19} \mathrm{C}\right)$

$V$ : FV hücrenin çıkış gerilimi

I: FV hücrenin çıkış akımı

$R_{s}$ : Hücrenin iç direnci

$R_{p}$ : Paralel kaçak akım direnci

$A$ : Diyotun kalite faktörü

$k$ : Boltzman sabiti $\left(1,3806505^{*} 10^{-23} \mathrm{~J} / \mathrm{K}\right)$

$T$ : FV hücrenin Kelvin cinsinden sıcaklığ temsil etmektedir [2,14-15].

Kullanılan FV panelin özellikleri Tablo 1'de verilmiștir.

Tablo 1. FV panelin özellikleri.

\begin{tabular}{ll}
\hline FV Panelin Özellikleri & Değerleri \\
\hline Maksimum güç $\left(P_{\max }\right)$ & $60 \mathrm{~W}$ \\
Maksimum gerilim $\left(V_{m p}\right)$ & $17,1 \mathrm{~V}$ \\
Maksimum akım $\left(I_{m p}\right)$ & $3,5 \mathrm{~A}$ \\
Kısa devre akımı $\left(I_{s c}\right)$ & $3,8 \mathrm{~A}$ \\
Açık devre gerilimi $\left(V_{o c}\right)$ & $21,1 \mathrm{~V}$ \\
Hücre sayısı $(\mathrm{n})$ & $36 \mathrm{Adet}$
\end{tabular}

Matematiksel eșdeğer devre modeli kullanılarak FV panelin $25{ }^{\circ} \mathrm{C}$ sicaklıkta ve $200,400,600$, $800,1000 \mathrm{~W} / \mathrm{m}^{2}$ güneş ışınım değişimlerinde PSIM benzetim programında elde edilen akımgerilim ve güç-gerilim karakteristikleri Şekil 2'de verilmiştir.

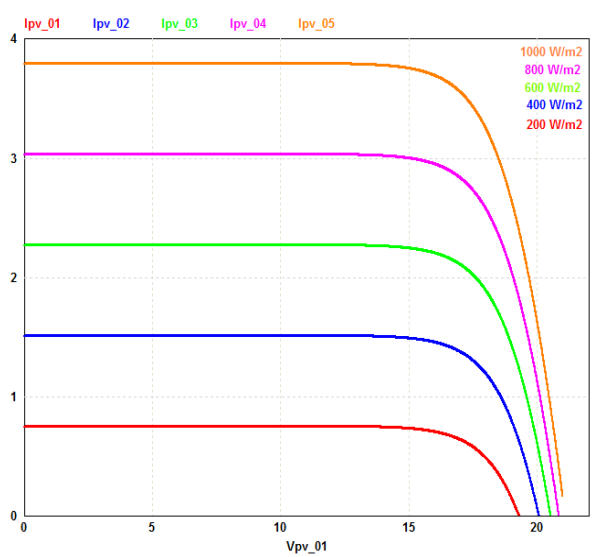

(a) 


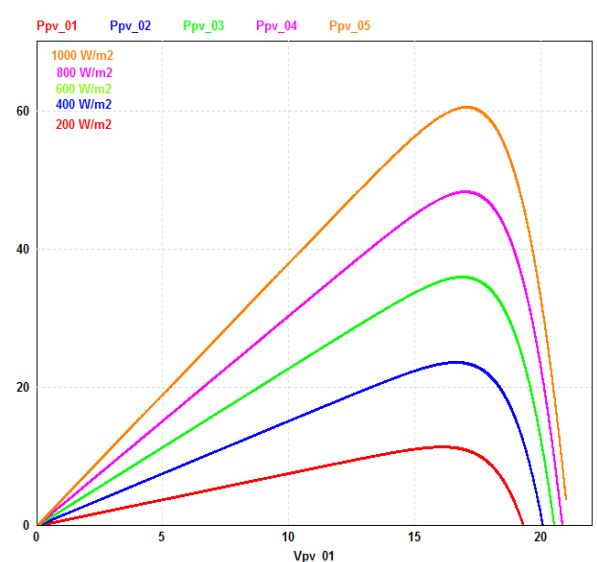

(b)

Şekil 2. FV panelin karakteristikleri (a) Akımgerilim, (b) Güç-gerilim

\subsection{Gölgeli FV panelin matematiksel analizi}

Şekil 3'te seri bağlı FV paneller ile birlikte kısmi gölgeli olan panelin şekli verilmiştir.

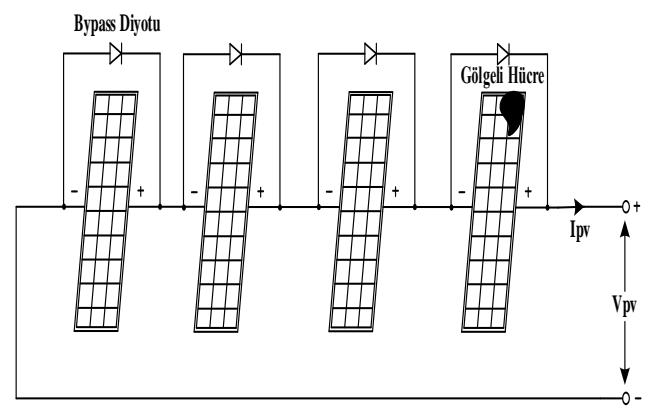

Şekil 3. Seri bağlı FV panellerde kısmi gölgelenme durumu

Kısmi gölgelenme durumundaki panelin kısa devre akımı $\left(I_{s c}=0\right)$ sıfır olur. Bu durumda devreden geçen akım, gölgelenmiş olan hücrelerde paralel direnç üzerinden geçmektedir. Paralel direncin değeri seri dirence göre çok yüksek olduğundan gölgelenmiş olan panelin gerilimi düşer. Özellikle gölgelenme miktarının fazla olduğu durumlarda seri bağlı FV panellerin toplam gerilimi ve gücü önemli ölçüde düşmektedir. Hücre sayısı $n$ olan panelin tüm hücreleri güneş ışığı altında iken FV panelin gerilimi $V_{p v n}$, tek hücresi gölgelenmiş FV panelin gerilimi ise $V_{p v s}$ olup, gölgelenmiş panelin gerilimi eşitlik (2) deki gibi hesaplanır $[7,13]$.

$$
V_{p v s}=V_{p v n}-\left(R_{p}+R_{s}\right) * I_{p v}-\frac{V_{p v n}}{n}
$$

Seri bağlı sistemler için gölgelenme miktarının düşük olduğu durumlarda gölgelenmiş olan panelin akımı, sistemin akımını oluşturur. $\mathrm{Bu}$ durum sistem akımının sinırlandırılmasına neden olarak güç kaybına yol açar. Oluşan bu güç kaybı gölgelenmiş hücrelerde ısı kaybı oluşturur. Oluşan güç kaybının azaltılması ve panel üzerindeki sıcak noktaların engellenebilmesi için bypass diyotu kullanılır. Bypass diyotu panele parallel bağlanarak akımın diyot üzerinden geçmesi sağlanır ve panelin zarar görmesi engellenir. Bypass diyotunun kullanılması ile birlikte bir genel güç noktası, bir de yerel güç noktası oluşur. Gölgelenmiş panel sayısının artması durumunda gölgelenmenin oluştuğu panel sayısı kadar yerel güç noktaları oluşur. Yerel güç noktasında çalışan sistemde güç kayıpları fazladır. Eğer sistem genel güç noktasında sürekli olarak çalıştırılırsa güç kaybı daha az olur [16-18].

\section{Benzetim Sonuçları}

Çalıșmada önce 2 adet FV panel seri bağlanmıștır. $\mathrm{Bu} \mathrm{FV}$ panellerden birinin güneș ışınım değeri sürekli olarak $1000 \mathrm{~W} / \mathrm{m}^{2}$ iken, diğer panel gölgesiz (\%0), $\% 20, \% 40, \% 60$ ve $\% 80$ gölgelenmeye maruz kaldığında bypass diyotunun kullanılıp kullanılmaması durumuna göre kayıp analizi yapılmıştır. Çalışma PSIM benzetim programında incelenmiştir. Daha sonra 4 adet FV panel seri bağlanmıș ve bunlardan 3'ünün sürekli olarak $1000 \mathrm{~W} / \mathrm{m}^{2}$ tam güneş ışığı altında çalıştığı, diğer panelin ise gölgesiz $(\% 0), \% 20, \% 40, \% 60$ ve $\% 80$ gölgelenmeye maruz kaldığında bypass diyotunun kullanılıp kullanılmaması durumuna göre kayıp analizi yapılmıștır. Son olarak 6 adet FV panel seri bağlanmış bunlardan 5 'inin tam güneş ışı̆̆ı altında birinin ise gölgesiz (\%0), $\% 20, \% 40, \% 60$ ve $\% 80$ gölgelenmeye maruz kaldığında bypass diyotunun kullanılıp kullanılmaması durumuna göre kayıp analizi yapılmıștır. Yapılan bu çalışmada, seri bağlanan FV panel sayısının arttırılıp sistemin toplam gölgelenme miktarının düşmesi sonucu bypass diyotunun kullanılıp kullanılmamasına göre meydana gelen kayıp değerlerinin sisteme olan etkisi incelenmiștir. 
DEÜ FMD 23(68), 621-630, 2021

\subsection{2 adet seri bağlı FV panelde gölgelenme}

Seri bağlı FV sistemde kısmi gölgelenme durumunun incelenebilmesi için Şekil 4'teki devre PSIM benzetim programinda oluşturulmuştur.

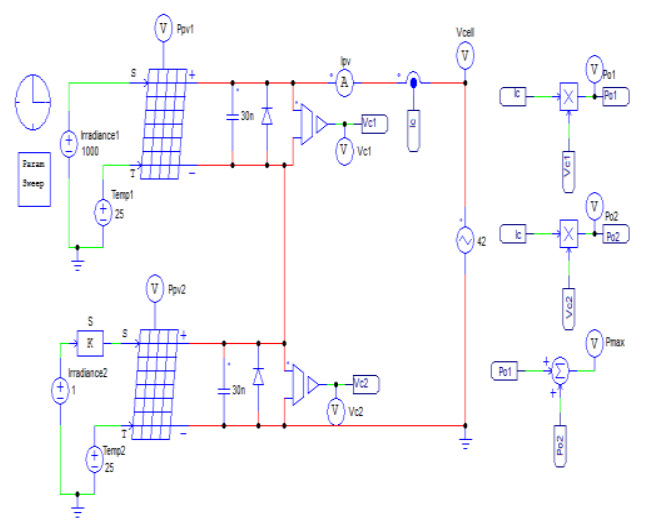

Şekil 4. Seri bağlı FV panellerde kısmi gölgelenme durumunun incelenmesi

Öncelikle bypass diyotunun bulunduğu 2 adet seri bağlı FV panelde, panellerden birinin tam güneş ışınımı altında $\left(1000 \mathrm{~W} / \mathrm{m}^{2}\right)$ diğerinin ise kademeli olarak $\% 0, \% 20, \% 40, \% 60$ ve $\% 80$ gölgelenme durumuna ait benzetim sonuçları Şekil 5'te gösterilmiştir.

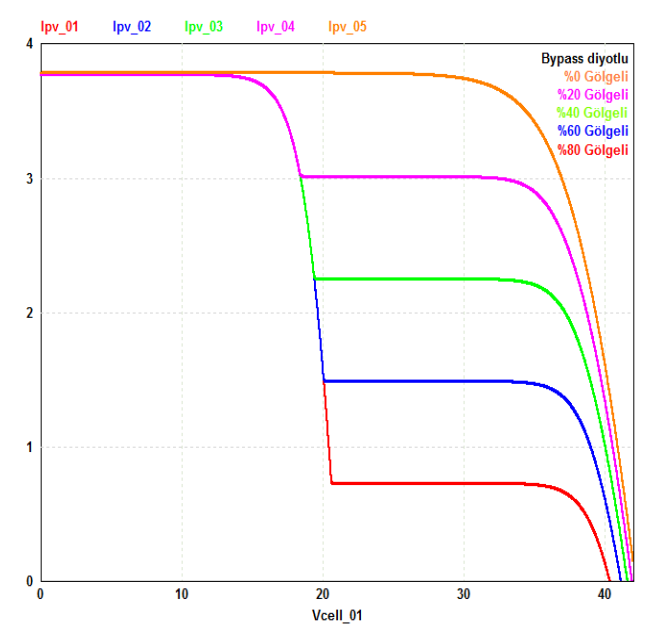

(a)

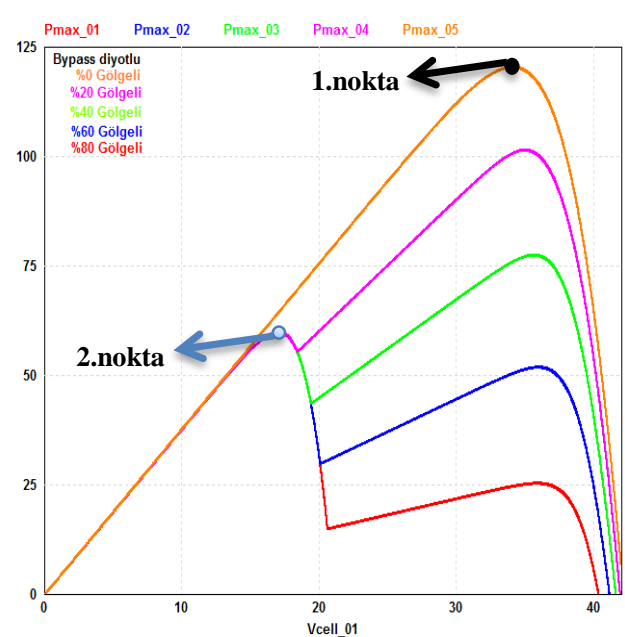

(b)

Şekil 5. Bypass diyotlu 2 adet seri bağlı FV panelin karakteristikleri (a) Akım-gerilim, (b) Güç-gerilim

Şekil 5'ten de görüleceği üzere kısmi gölgelenmeye maruz kalmış bypass diyotunun bağlı olduğu sistemlerde 2 adet maksimum güç noktası oluşmaktadır. Bu güç noktalarından biri olan genel güç noktası her zaman yerel güç noktasından büyük değerde olur. Genel güç noktası, $\% 0, \quad \% 20$ ve $\% 40$ gölgelenme durumunda 1.noktada oluşurken yerel güç noktası 2.noktada oluşmaktadır. Gölgelenme $\% 60$ ile $\% 80$ olduğunda genel güç noktası 2.noktaya kaymıştır. Kısmi gölgelenmeye maruz kalmış bypass diyotsuz sistemin karakteristikleri Şekil 6'da verilmiştir.

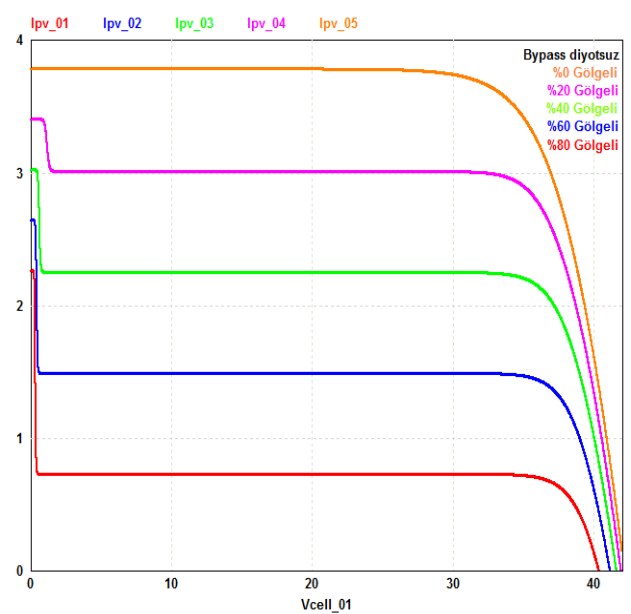

(a) 


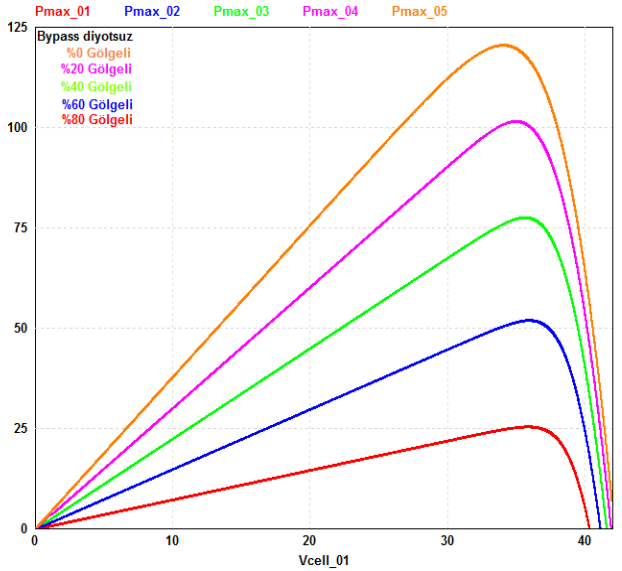

(b)

Şekil 6. Bypass diyotsuz 2 adet seri bağlı FV panelin karakteristikleri (a) Akım-gerilim, (b) Güç-gerilim
Şekil 6'dan da görüleceği üzere bypass diyotunun bağlı olmadığı 2 adet seri bağlı FV panel sisteminde akımın düștüğü ve bu durumda akımın sınırlandırıldığı görülmektedir. Bunun sonucunda sistemde toplam gölgelenme miktarı \%30 olduğunda \%56,69 kayıp oluşurken, toplam \%40 gölgelenme olduğunda ise kayıp \%78,77 olmaktadır. Yani; gölgelenme oranı arttıkça verimlilik düşürek kayıp oranı artmaktadır. Bypass diyodunun bağlı olduğu sistemde ise toplam gölgelenme oranı $\% 30$ ve $\% 40$ iken kayıp oranı \%50'dir. Bu durum bypass diyotlu sistemde gölgelenme miktarının belirli bir sınır değerinden sonra kayıp oranını arttırmadığını, kayıp oranının aynı değerde kaldığını göstermektedir. Tablo 2'de kısmi gölgelenmeye maruz kalmıș 2 adet seri bağlı FV panelde bypass diyotunun bağlı olduğu ve olmadı̆̆ durumlardaki güç, gerilim, verimlilik ve toplam gölgelenme oranına ait sayısal veriler sunulmuştur.

Tablo 2.2 adet seri bağlı FV panelde bypass diyotlu ve bypass diyotsuz sisteme ait veriler.

\begin{tabular}{|c|c|c|c|c|c|c|c|c|c|c|}
\hline \multirow{2}{*}{ Parametre } & \multicolumn{5}{|c|}{$\begin{array}{l}2 \text { Adet Seri Bağlı FV Panel } \\
\text { Bypass Diyotlu }\end{array}$} & \multicolumn{5}{|c|}{$\begin{array}{l}2 \text { Adet Seri Bağlı FV Panel } \\
\text { Bypass Diyotsuz }\end{array}$} \\
\hline & $\% 0$ & $\% 20$ & $\% 40$ & $\% 60$ & $\% 80$ & $\% 0$ & $\% 20$ & $\% 40$ & $\% 60$ & $\% 80$ \\
\hline Güç (W) & 120,14 & 101,66 & 77,69 & 60,09 & 60,09 & 120,14 & 101,66 & 77,69 & 52,04 & 25,51 \\
\hline Gerilim (V) & 34,05 & 34,96 & 35,73 & 17,11 & 17,11 & 34,05 & 34,96 & 35,73 & 36,08 & 36,07 \\
\hline Verimlilik (\%) & 100 & 84,61 & 64,66 & 50 & 50 & 100 & 84,61 & 64,66 & 43,31 & 21,23 \\
\hline $\begin{array}{l}\text { Sistemin toplam } \\
\text { gölgelenme oranı } \\
\text { (\%) }\end{array}$ & 0 & 10 & 20 & 30 & 40 & 0 & 10 & 20 & 30 & 40 \\
\hline
\end{tabular}

\subsection{4 adet seri bağlı FV panelde gölgelenme}

Bypass diyotunun bulunduğu 4 adet seri bağlı FV panelde panellerden üçünün tam güneș ışınımı altında $\left(1000 \mathrm{~W} / \mathrm{m}^{2}\right)$, birinin ise kademeli olarak $\% 0, \% 20, \% 40, \% 60$ ve $\% 80$ gölgelenme durumuna ait benzetim sonuçları Şekil 7'de gösterilmiştir.

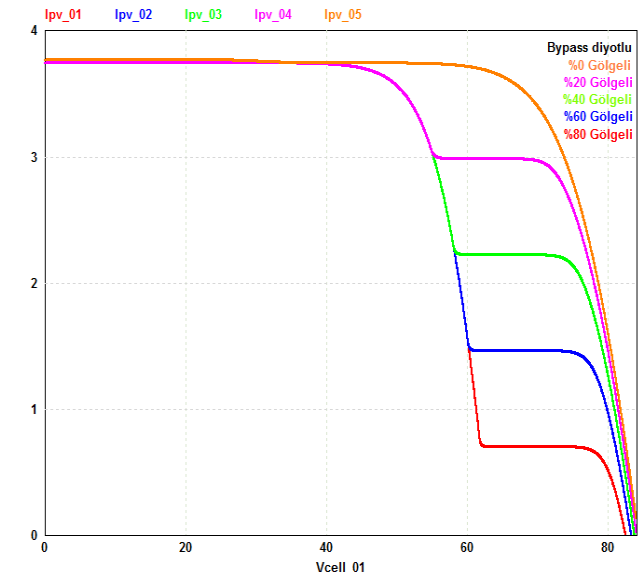

(a) 


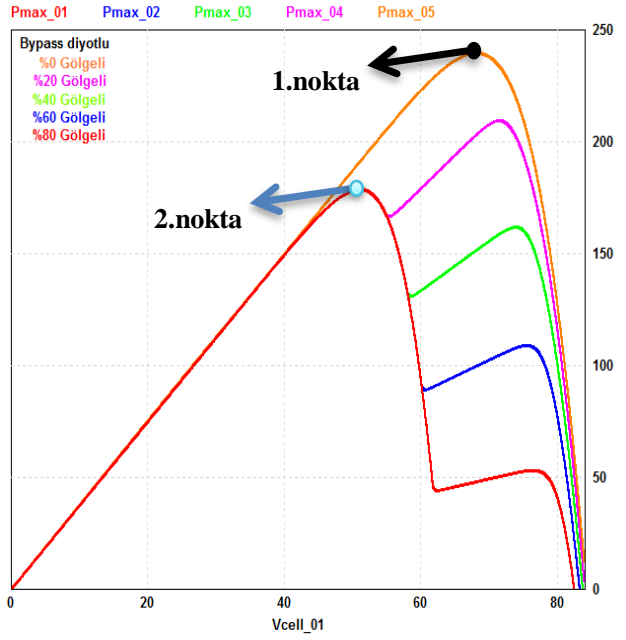

(b)

Şekil 7. Bypass diyotlu 4 adet seri bağlı FV panelin karakteristikleri (a) Akım-gerilim, (b) Güç-gerilim

Şekil 7'den de görüldüğü üzere bypass diyotlu 4 adet seri bağlı FV panelden biri $\% 0$ ve $\% 20$ kısmi gölgelenmeye maruz kaldığında genel güç noktası 1. noktada oluşurken $\% 40, \% 60$ ve $\% 80$ kısmi gölgelenme durumunda genel güç noktası 2. noktaya kaymıştır. Kısmi gölgelenmeye maruz kalmış bypass diyotsuz sistemin karakteristikleri Şekil 8'de verilmiștir.

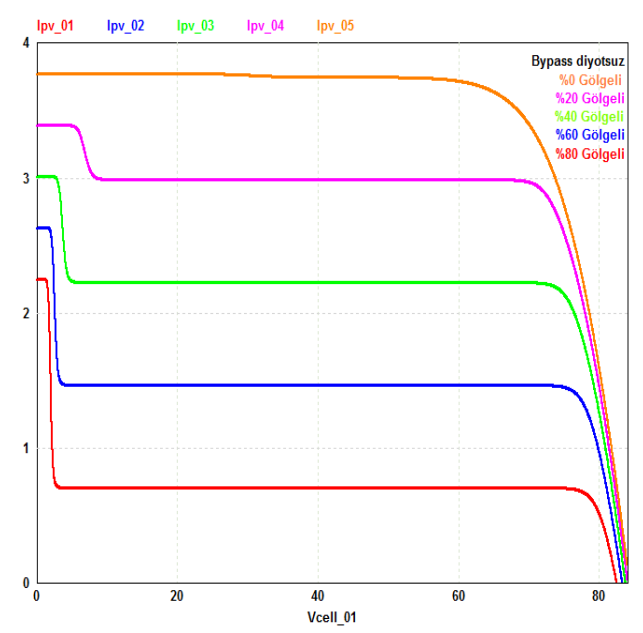

(a)

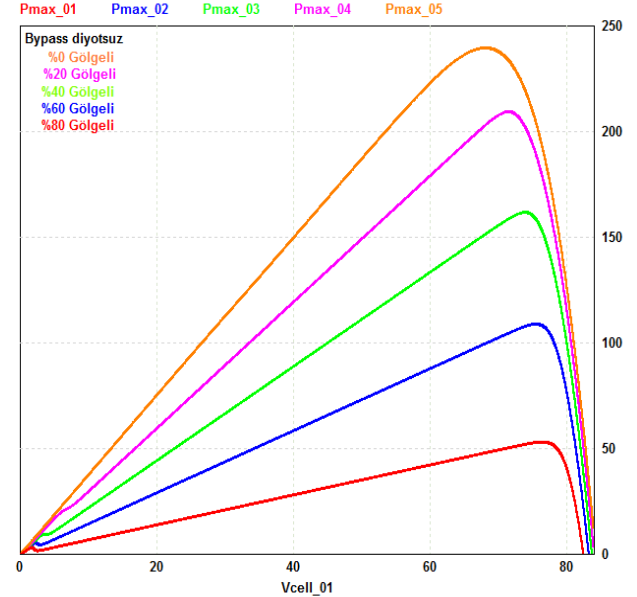

(b)

Şekil 8. Bypass diyotsuz 4 adet seri bağlı FV panelin karakteristikleri (a) Akım-gerilim, (b) Güç-gerilim

Bypass diyotunun bağlı olmadığı 4 adet seri bağlı FV panel sisteminde toplam gölgelenme miktarı \%10 olduğunda \%32,63 kayıp, toplam $\% 15$ gölgelenme olduğunda $\% 54,47$ kayıp ve toplam \%20 gölgelenme olduğunda ise $\% 77,96$ kayıp oluşmuştur. Yani; seri bağlı FV panel sayısı arttırılıp toplam gölgelenme oranı düştükçe bypass diyotsuz sistemler bundan daha çok etkilenerek kayıplar daha fazla olmaktadır. Bypass diyodunun bağlı olduğu sistemde ise toplam gölgelenme oranı $\% 10$, $\% 15$ ve $\% 20$ iken kayıp sabit bir şekilde $\% 24,6$ olarak kalmıştır. $\mathrm{Bu}$ durumda, düşük gölgelenme oranlarında dahi bypass diyotsuz sistemlerde bypass diyotlu sistemlere göre kayıpların daha fazla olduğu ve sistemin veriminin düştüğü görülmektedir. Tablo 3 'te kısmi gölgelenmeye maruz kalmış 4 adet seri bağlı FV panelde bypass diyotunun bağlı olduğu ve olmadığı durumlardaki güç, gerilim, verimlilik ve toplam gölgelenme oranına ait sayısal veriler sunulmuştur. 
DEÜ FMD 23(68), 621-630, 2021

Tablo 3. 4 adet seri bağlı FV panelde bypass diyotlu ve bypass diyotsuz sisteme ait veriler.

\begin{tabular}{|c|c|c|c|c|c|c|c|c|c|c|}
\hline \multirow{2}{*}{ Parametre } & \multicolumn{5}{|c|}{$\begin{array}{c}\text { 4 Adet Seri Bağlı FV Panel } \\
\text { Bypass Diyotlu }\end{array}$} & \multicolumn{5}{|c|}{$\begin{array}{l}\text { 4 Adet Seri Bağlı FV Panel } \\
\text { Bypass Diyotsuz }\end{array}$} \\
\hline & $\% 0$ & $\% 20$ & $\% 40$ & $\% 60$ & $\% 80$ & $\% 0$ & $\% 20$ & $\% 40$ & $\% 60$ & $\% 80$ \\
\hline Güç (W) & 240,28 & 209,4 & 181,18 & 181,18 & 181,18 & 240,28 & 209,4 & 161,88 & 109,4 & 52,97 \\
\hline Gerilim (V) & 68,09 & 71,74 & 51,12 & 51,12 & 51,12 & 68,09 & 71,74 & 74,09 & 75,9 & 76,46 \\
\hline Verimlilik (\%) & 100 & 87,14 & 75,4 & 75,4 & 75,4 & 100 & 87,14 & 67,37 & 45,53 & 22,04 \\
\hline $\begin{array}{l}\text { Sistemin toplam } \\
\text { gölgelenme oranı } \\
(\%)\end{array}$ & 0 & 5 & 10 & 15 & 20 & 0 & 5 & 10 & 15 & 20 \\
\hline
\end{tabular}

3.3. 6 adet seri bağlı FV panelde gölgelenme

Bypass diyotunun bulunduğu 6 adet seri bağlı FV panelde panellerden 5 'inin tam güneş ışınımı altında, birinin ise kademeli olarak \%0, \%20, $\% 40, \% 60$ ve $\% 80$ gölgelenme durumuna ait benzetim sonuçları Şekil 9'da gösterilmiştir.

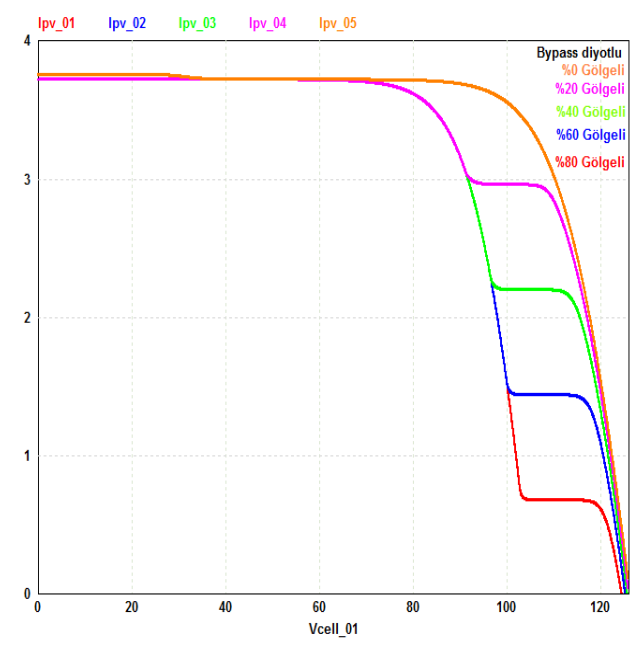

(a)

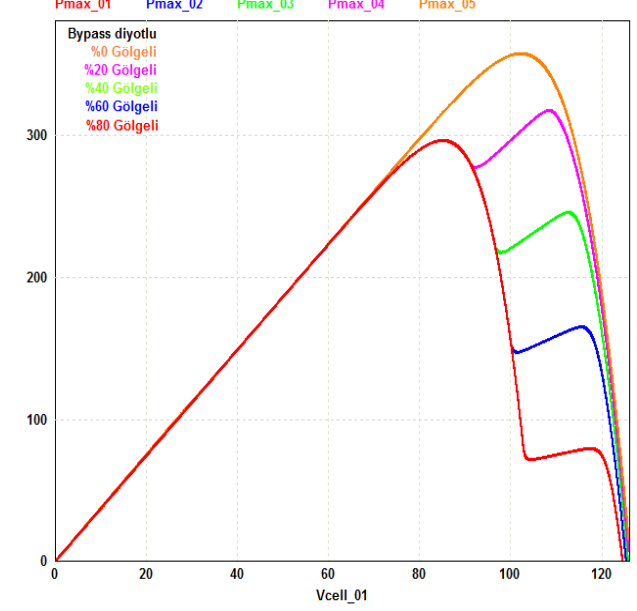

(b)

Şekil 9. Bypass diyotlu 6 adet seri bağlı FV panelin karakteristikleri (a) Akım-gerilim, (b) Güç-gerilim

Bypass diyotlu 6 adet seri bağlı FV panelden biri $\% 0$ ve $\% 20$ kısmi gölgelenmeye maruz kaldığında genel güç noktası 1 . noktada oluşurken yerel güç noktası 2. noktada oluşmuştur. $\% 40, \% 60$ ve $\% 80$ kismi gölgelenme durumunda ise genel güç noktası 2. noktaya, yerel güç noktası ise 1. noktaya kaymıştır. Kısmi gölgelenmeye maruz kalmış bypass diyotsuz sistemin karakteristikleri Şekil 10 'da verilmiştir. 


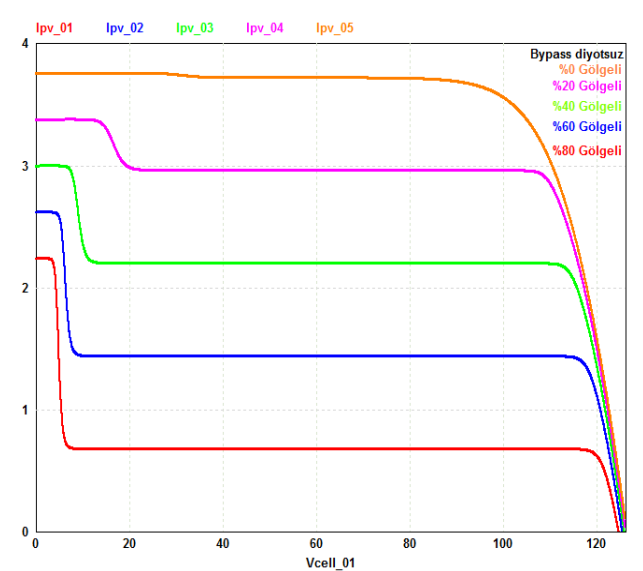

(a)

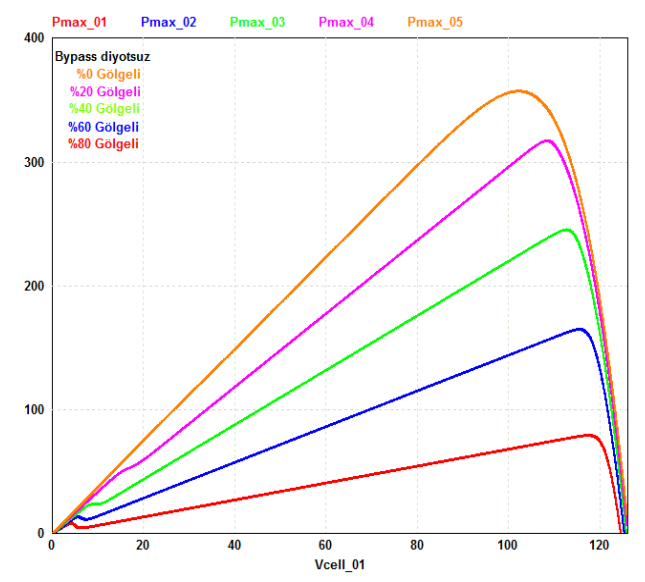

(b)

Şekil 10. Bypass diyotsuz 6 adet seri bağlı FV panelin karakteristikleri (a) Akım-gerilim, (b) Güç-gerilim

Bypass diyotunun bağlı olmadığ 6 adet seri bağlı FV panel sisteminde toplam gölgelenme miktarı \%6,7 olduğunda \%31,3 kayıp, toplam $\% 10$ gölgelenme olduğunda \%53,82 kayıp ve toplam \%14 gölgelenme olduğunda ise $\% 77,76$ kayıp oluşmuştur. Yani; seri bağlı FV panel sayısı arttırılıp toplam gölgelenme oranı düştükçe bypass diyotsuz sistemler bundan daha çok etkilenerek kayıplar daha fazla olmaktadır. Bypass diyodunun bağlı olduğu sistemde ise toplam gölgelenme oranı $\% 6,7$, $\% 10$ ve \%14 iken kayıp sabit bir șekilde \%17,2 olarak kalmıștır. Bypass diyotlu sistemde seri bağlı FV panel sayısı arttırılıp gölgelenme miktarı düştükçe kayıp oranı da düşmektedir. Tablo 4'te kısmi gölgelenmeye maruz kalmış 6 adet seri bağlı FV panelde bypass diyotunun bağlı olduğu ve olmadığı durumlardaki güç, gerilim, verimlilik ve toplam gölgelenme oranına ait sayısal veriler sunulmuştur.

\section{Tartışma ve Sonuç}

Bu çalışmada, kısmi gölgelenmeye maruz kalmış seri bağlı FV sistemlerde panel sayısının arttırılmasinın bypass diyotlu ve diyotsuz sistemlerde meydana getirmiş olduğu kayıplar incelenmiştir. Çalışmada sırasıyla 2, 4 ve 6 adet seri bağlı FV panellerde panel sayıları arttırılmış, toplam kısmi gölgelenme oranı düşürülerek sistemin verimliliği ele alınmıştır. Bypass diyotunun bağlı olmadığı 2 adet seri bağlı FV sistemlerde $\% 10$ ve $\% 20$ kayıp oranları diyotlu sistemler ile aynı verimliliktedir. Fakat gölgelenme oranı $\% 30$ ve $\% 40$ olduğunda, bypass diyotsuz sistemlerde bypass diyotlu sistemlere nazaran kayıp oranlarının daha fazla olduğu ve verimliliğin düştüğü görülmektedir. $\mathrm{Bu}$ durum, 4 ve 6 adet seri bağlı FV sistemler için de geçerlidir. 4 ve 6 adet seri bağlı bypass diyotsuz sistemlerde gölgelenme oranı düşürülse de kayıp oranı artmaktadır. $\mathrm{Bu}$ durum, bypass diyotunun yer almadiğı sistemlerde seri bağlı FV panel sayısının arttırılması durumunda gölgelenme oranının düşük kalsa bile sistemi çok fazla etkileyerek kayıpların yüksek olduğunu göstermektedir. Bunun temel nedeni diyotsuz seri bağlı FV sistemde, sistem akımının düşerek akımın sinırlandirılıyor olmasıdır. Bypass diyotlu sistemlerde ise seri bağlanan FV panel sayısı artsa da toplam gölgelenme oranı azaldıkça kayıp oranının düşük kaldığı ve bu durumun sistemi daha az etkilediği görülmektedir. $\mathrm{Bu}$ çalışmanın sonucu olarak kısmi gölgelenmeye maruz kalmış sistemlerde seri bağlanan FV panel sayısının arttırılması ile bypass diyotsuz sistemlerde gölgelenme etkisinin kayıpları arttırarak verimliliği düşürdüğü, bypass diyotlu sistemlerde ise kayıpların düşük kalarak sistemi daha az etkilediği görülmektedir. 
DEÜ FMD 23(68), 621-630, 2021

Tablo 4. 6 adet seri bağlı FV panelde bypass diyotlu ve bypass diyotsuz sisteme ait veriler.

\begin{tabular}{|c|c|c|c|c|c|c|c|c|c|c|}
\hline \multirow{2}{*}{ Parametre } & \multicolumn{5}{|c|}{$\begin{array}{c}6 \text { Adet Seri Bağlı FV Panel } \\
\text { Bypass Diyotlu }\end{array}$} & \multicolumn{5}{|c|}{$\begin{array}{c}6 \text { Adet Seri Bağlı FV Panel } \\
\text { Bypass Diyotsuz }\end{array}$} \\
\hline & $\% 0$ & $\% 20$ & $\% 40$ & $\% 60$ & $\% 80$ & $\% 0$ & $\% 20$ & $\% 40$ & $\% 60$ & $\% 80$ \\
\hline Güç (W) & 357,41 & 317,37 & 296,23 & 296,23 & 296,23 & 357,41 & 317,37 & 245,57 & 165,06 & 79,52 \\
\hline Gerilim (V) & 102,23 & 108,33 & 84,97 & 84,97 & 84,97 & 102,23 & 108,33 & 112,74 & 115,69 & 117,79 \\
\hline Verimlilik (\%) & 100 & 88,79 & 82,88 & 82,88 & 82,88 & 100 & 88,79 & 68,7 & 46,18 & 22,24 \\
\hline $\begin{array}{l}\text { Sistemin toplam } \\
\text { gölgelenme } \\
\text { oranı (\%) }\end{array}$ & 0 & 3,4 & 6,7 & 10 & 14 & 0 & 3,4 & 6,7 & 10 & 14 \\
\hline
\end{tabular}

\section{Kaynakça}

[1] Mert, B.D., Ekinci, F., Demirdelen, T. 2019. Effect of Partial Shading Conditions on Off-Grid Solar PV/Hydrogen Production in High Solar Energy Index Regions, International Journal of Hydrogen Energy, Cilt. 44(51), s. 27713-27725. DOI: 10.1016/j.ijhydene.2019.09.011

[2] Karafil, A., Özbay, H., Kesler, M. 2016. Sıcaklık ve Güneş Işınım Değişimlerinin Fotovoltaik Panel Gücü Üzerindeki Etkilerinin Simülasyon Analizi. EEB 2016 Elektrik-Elektronik ve Bilgisayar Sempozyumu, 11-13 Mayıs, Tokat, 106-111.

[3] Nguyen, K.H., Kakinaka, M. 2019. Renewable Energy Consumption, Carbon Emissions, and Development Stages: Some Evidence from Panel Cointegration Analysis, Renewable Energy, Cilt. 132, s. 1049-1057. DOI: 10.1016/j.renene.2018.08.069

[4] Lehtola, T., Zahedi, A. 2019. Solar Energy and Wind Power Supply Supported by Storage Technology: A Review, Sustainable Energy Technologies and Assessments, Cilt. 35, s. 25-31. DOI: 10.1016/j.seta.2019.05.013

[5] Ullah, A., Imran, H., Maqsood, Z., Butt, N.Z. 2019. Investigation of Optimal Tilt Angles and Effects of Soiling on PV Energy Production in Pakistan, Renewable Energy, Cilt. 139, s. 830-843. DOI: 10.1016/j.renene.2019.02.114

[6] Reimuth, A., Locherer, V., Danner, M., Mauser, W. 2020 How Do Changes in Climate and Consumption Loads Affect Residential PV Coupled Battery Energy Systems?, Energy, Cilt. 198, s. 117339. DOI: 10.1016/j.energy.2020.117339

[7] Ünlü, M., Çamur, S., Arifoğlu, B. 2015. Fotovoltaik Enerji Dönüșüm Sistemlerinde Parçalı Gölgelenme Durum Analizi, Elektrik Enerji, Elektrik, Aydınlatma, Elektronik ve Otomasyon Mühendisliği Dergisi, Cilt. 314, s. 83-87.

[8] Teo, J.C., Tan, R.H., Mok, V.H., Ramachandaramurthy, V.K., Tan, C. 2020. Impact of Bypass Diode Forward Voltage on Maximum Power of A Photovoltaic System Under Partial Shading Conditions, Energy, Cilt. 191, s. 116491. DOI: 10.1016/j.energy.2019.116491

[9] Satpathy, P.R., Sharma, R. 2020. Parametric Indicators for Partial Shading and Fault Prediction in Photovoltaic Arrays With Various Interconnection Topologies,
Energy Conversion and Management, Cilt 219, s. 113018. DOI: 10.1016/j.enconman.2020.113018

[10] Silvestre, S., Boronat, A., Chouder, A. 2009. Study of Bypass Diodes Configuration on PV Modules, Applied Energy, Cilt. 86(9), s. 1632-1640. DOI: 10.1016/j.apenergy.2009.01.020

[11] Wen, Z., Chen, J., Cheng, X., Niu, H., Luo, X. 2019. A New and Simple Split Series Strings Approach for Adding Bypass Diodes in Shingled Cells Modules to Reduce Shading Loss, Solar Energy, Cilt. 184, s. 497-507. DOI: 10.1016/j.solener.2019.03.099

[12] Abdulazeez, M., Iskender, I. 2011. Simulation and Experimental Study of Shading Effect on Series and Parallel Connected Photovoltaic PV Modules. In 7th IEEE International Conference on Electrical and Electronics Engineering (ELECO), 1-4 December, Bursa, I-28-I-32.

[13] Karafil, A., Ozbay, H. 2017. Investigation of the Effect of Partial Shadowing With Solar Array Simulator. International Conference on Advances and Innovations in Engineering (ICAIE), 10-12 May, Elazığ, 424-427.

[14] Yin, O.W., Babu, B.C. 2018. Simple and Easy Approach for Mathematical Analysis of Photovoltaic (PV) Module Under Normal and Partial Shading Conditions, Optik, Cilt. 169, s. 48-61. DOI: 10.1016/j.ijleo.2018.05.037

[15] Karaca, M., Mamizadeh, A., Genc, N., Sular, A. 2019. Analysis of Passive Filters for PV Inverters Under Variable Irradiances. In 8th IEEE International Conference on Renewable Energy Research and Applications (ICRERA), 3-6 November, Brasov, 680685.

[16] Teo, J.C., Tan, R.H., Mok, V.H., Ramachandaramurthy, V.K., Tan, C. 2018. Impact of Partial Shading on the PV Characteristics and the Maximum Power of A Photovoltaic String, Energies, Cilt. 11(7), s. 1860. DOI: 10.3390/en11071860

[17] Hu, K., Cao, S., Li, W., Zhu, F. 2019. An Improved Particle Swarm Optimization Algorithm Suitable for Photovoltaic Power Tracking Under Partial Shading Conditions, IEEE Access, Cilt. 7, s. 143217-143232. DOI: 10.1109/ACCESS.2019.2944964

[18] Ma, J., Pan, X., Man, K. L., Li, X., Wen, H., Ting, T.O. 2018. Detection and Assessment of Partial Shading Scenarios on Photovoltaic Strings, IEEE Transactions on Industry Applications, Cilt. 54(6), s. 6279-6289. DOI: 10.1109/TIA.2018.2848643 